\title{
Inactivated Trivalent Vaccine for Leptospira in Andhra Pradesh
}

\author{
Dr. D. Rani Prameela ${ }^{1}$, Dr. D. Sreenivasulu ${ }^{2}$, Dr. P. Eswara Prasad ${ }^{3}$, Dr. P. Vijayachari ${ }^{4}$, \\ Dr. S. Vijaya Lakshmi ${ }^{5}$ \\ ${ }^{1,2,5}$ Department of Veterinary Microbiology, C.V.SC., Sri Venkateswara Veterinary University, Tirupati, Andhra Pradesh, India \\ ${ }^{3}$ Department of Veterinary Biochemistry, C.V.SC., Sri Venkateswara Veterinary University, Tirupati, Andhra Pradesh, India \\ ${ }^{4}$ Director, ICMR, Port Blair, Center for Diagnosis and typing of leptospira, Andaman and Nicobar Islands
}

\begin{abstract}
Leptopsirosis, the world wide zoonosis is considered as re-emerging disease. Besides economic losses caused by Leptopsira to animal production, its zoonotic character makes it an important public health problem Seroepidemiological studies conducted using MAT indicated the dominance of L.hardjo, L.grripotyposa and L. autumnalis in the state. Hence, serovars hardjo, grripotyposa and autumnalis were selected as vaccine candidates for the preparation of trivalent vaccine. The homology and purity of the vaccine candidates were checked using reference antisera procured from ICMR, Port Blair, Center for Diagnosis and typing of leptospira, Andaman and Nicobar Islands and also using hyper immune sera raised against the respective serovars in the present study. The candidate vaccine strains were adopted to low protein medium containing 0.2 percent Bovine serum albumin (BSA) and adjusted the concentration to $2 \times 10^{9}$ cells $/ \mathrm{ml}$. The leptospiral organisms were inactivated with 0.5 percent formalin and adjuvanted with aluminum hydroxide (vaccine-I and Montanide (vaccine-II).The vaccines prepared were evaluated for sterility, safety and potency tests. The immune responses were studied in rabbits using both the types of adjuvanted vaccines and could not find any significant differences between the vaccines. The immune response was found to be satisfactory with both the types of vaccines up to 150 days of post vaccinated period tested. The present work has been carried out during 2006 to 2010.
\end{abstract}

Key words: Re-emerging, vaccine candidates, low protein medium and Immune response

\section{Introduction}

Leptospirosis is a wide spread disease [23] caused by a spirochete Leptopsira, which affects almost all mammals [4]. Vaccination is the only reliable means of controlling leptospirosis in all species of animals. Inactivated and attenuated vaccines are especially suitable as veterinary vaccines [24]. The majority of vaccines are formalin inactivated bacterins which contain one or more serotypes [22], [13] mixed with aluminum hydroxide. Immunity to leptospires is serovar specific [7]. The study was conducted to identify the prevailing serovars in Andhra Pradesh.

A total of 2,320 sera samples representing different districts of the state were subjected to MAT and observed higher prevalence against $L$. grippotyphosa, $L$. hardjo and $L$. autumnalis, the predominant serovars circulating in Andhra Pradesh. L. hardjo was also isolated and are being maintained in the laboratory. The local serovars could not be used in the study for development of vaccine for want of detailed antigenic and genotypic characterization. Hence, the reference strains i.e. grippotyposa, hardjo and autumnalis obtained from reference center ICMR, Port Blair, Andaman and Nicobar Islands were used for preparation of vaccine.

\section{Material and Methods}

\subsection{Selection of Serovars of Leptospira}

L. grippotyphosa, L. hardjo and L. autumnalis, the commonly circulating serovars were used for the preparation of vaccine. Leptospira bacterins were prepared as per the production outline of British Pharmacopoeia [5].

\subsection{Cultivation of leptospires}

Preparation of low protein medium

Low protein medium was prepared accordingly to the protocol followed at Regional medical research center, Port Blair, Andaman and Nicobar islands.

\subsection{Preparation of charcoal treated tween 80}

Charcoal treated (CT) Tween 80 was prepared according to the method described by Bey and Jhonson [3]. Stock solutions of charcoal treated tween 80 were prepared by dissolving $20 \mathrm{~g}$ of Tween 80 in $200 \mathrm{ml}$ of distilled water. While the solution of tween is stirring, $40 \mathrm{~g}$ of activated charcoal was added gently to ensure homogeneous suspension of charcoal particles. The Tween was then carefully decanted from the charcoal sediment and centrifuged at $10,000 \mathrm{~g}$ for $1 \mathrm{~h}$ and sterilized using $0.22 \mu \mathrm{m}$ filter membrane. The stock solution of charcoal treated tween was stored at $4^{\mathrm{O}} \mathrm{C}$.

\subsection{Adaptation of leptospires to low protein medium}

EMJH media containing 10 percentages, 7.5 percentage, 5percentage, 2.5 percentage, 1 percentage and 0.2 percentage of BSA were prepared. They were distributed into $4 \mathrm{ml}$ of aliquots and checked for sterility by keeping at room temperature for a week. 5 to 7 day old cultures containing $2 \times 10^{9}$ organisms per $\mathrm{ml}$ were added to media containing 10percentage BSA and subcultured once in a week for three times. Later leptospiral serovars were further subcultured serially in media containing 7.5 percentages, 5 


\section{International Journal of Science and Research (IJSR) \\ ISSN (Online): 2319-7064}

Index Copernicus Value (2013): 6.14 | Impact Factor (2014): 5.611

percentage, 2.5 percentage, 1 percentage and 0.2 percentage of BSA for adaptation.

\subsection{Preparation of leptospira suspension}

The three serovars namely L.autumnalis, L.gripptotyphosa, and L.hardjo selected for preparation of vaccine were grown separately in cell culture bottles containing $18 \mathrm{ml}$ of the low protein medium. Two $\mathrm{ml}$ of leptospiral seed stock cultures were inoculated and incubated at $29^{\circ} \mathrm{C} \pm 1^{\circ} \mathrm{C}$ for 10 to 12 days. Cultures containing more than $2 \times 10^{9}$ organisms per $\mathrm{ml}$ were used as inoculum for further cultivation of organisms in bulk for preparation of vaccine.

Twenty $\mathrm{ml}$ of inoculum thus prepared containing L.autumnalis, L.gripptotyphosa and L.hardjo was inoculated in each of the three bottles containing $180 \mathrm{ml}$ of low protein medium. The cultures were incubated at $29^{\circ} \mathrm{C} \pm 1{ }^{\circ} \mathrm{C}$ for 10 to 12 days. The concentration of leptospires was adjusted to $2 \times 10^{9}$ leptospires per $\mathrm{ml}$ of each serovar for preparation of vaccine.

Before inactivation of the organisms the purity of the organisms were checked using dark field microscopy. If suspected for minor contamination the leptospiral organisms were passed through $0.22 \mu \mathrm{m}$ filters for clarity. Further, the cultures were also checked for sterility using blood agar medium, Saubourads dextrose agar medium and Thioglycollate medium in duplicates.

\subsection{Preparation of Vaccines}

The cultures thus obtained were inactivated with $0.5 \%$ formalin and adjuvanted with two types of adjuvants namely aluminium hydroxide and Montanide ISA 206 separately.

\subsubsection{Formalin inactivation}

The cultures thus obtained were inactivated by adding $1 \mathrm{ml}$ of formalin ( 0.5 percentage) to each bottle containing $200 \mathrm{ml}$ of leptospiral suspension. Later cultures were tested for success of inactivation. Inactivated cultures along with fresh leptospira cultures of L.autumnalis, L.gripptotyphosa, and L.hardjo were inoculated into $4.5 \mathrm{ml}$ of fresh EMJH liquid media, incubated for 14 days at $29^{\circ} \mathrm{C} \pm 1^{\circ} \mathrm{C}$ and examined the growth of leptospira under dark field microscope.

After confirming the successful inactivation the cultures were incubated at $37{ }^{\mathrm{O}} \mathrm{C}$ under stirring. The cultures were harvested by centrifugation at $14,000 \mathrm{~g}$ at $4^{0} \mathrm{C}$. The sediment was resuspended in PBS and washed thrice with PBS. Then the formalized leptospries were resuspended in PBS to a concentration of $2 \mathrm{X} 10^{9}$ organisms per $\mathrm{ml}$.

All the bacterins thus prepared were mixed in equal quantities together and bacterin suspension was aliquoted equally in two separate bottles.

\subsubsection{Aluminium hydroxide}

The bottle containing the bacterins were subjected to centrifugation and separated the pellet. The pellet was mixed with $20 \mathrm{ml}$ of aluminum hydroxide gel thoroughly and made upto $100 \mathrm{ml}$ using PBS. The vaccine produced was distributed in $2 \mathrm{ml}$ glass bottles labeled as Vaccine I and stored in refrigeration.

\subsubsection{Montanide ISA 206}

Similarly another bottle containing bacterins was also subjected to centrifugation and pellet was mixed with $46.2 \mathrm{ml}$ of Montanide ISA 206 and homogenized thoroughly. Later the volume was made up to $100 \mathrm{ml}$ with PBS. The vaccine was distributed into $2 \mathrm{ml}$ glass bottles, labelled and stored in refrigerator for future use as Vaccine II.

\section{Standardization of the Vaccine}

Standardization of the vaccines was done according to the British pharmacopoeia [5].

\section{Results}

Serovars namely $L$. grippotyphosa, $L$. hardjo and $L$. autumnalis were selected as candidate vaccine strains for the development of inactivated vaccine based on the studies conducted on seroprevalnece of leptospirosis in Andhra Pradesh. L. grippotyphosa, L. hardjo and L. autumnalis were found to be predominant serovars circulating in the state.

Antigenic property of the selected leptospiral serovars i.e. $L$. grippotyphosa, L. hardjo and L. autumnalis were examined using hyper immune sera inoculated into rabbits against the respective serovars. The selected $L$. grippotyphosa, $L$. hardjo and $L$. autumnalis reacted with respective reference sera and found to have higher titers in 1:10240, 1:2560 and 1:20480 respectively. Rabbits inoculated with $L$. grippotyphosa, L. hardjo and L. autumnalis were also found to have the titers of 1: 81920, 1:40960 and 1:40,960 respectively (Table.I).

Table 1: Results of antigenic properties of Leptospiral vaccine strains

\begin{tabular}{|c|c|c|}
\hline Serovar & $\begin{array}{c}\text { Titer with Reference } \\
\text { Serum }\end{array}$ & $\begin{array}{c}\text { Titer with } \\
\text { Hyperimmune serum }\end{array}$ \\
\hline L.grippotyphosa & 10,240 & 81,920 \\
\hline L.hardjo & 2,560 & 40,960 \\
\hline L.autumnalis & 20,480 & 40,960 \\
\hline
\end{tabular}

The organisms were adopted to grow from high protein to low protein (up to 0.2 percent) concentration of BSA. In the process of adaptation, growth of leptospires in low protein medium containing 0.2 percent BSA, the organisms were found to grow at a concentration of $2 \times 10^{9}$ organisms per $\mathrm{ml}$ by $10^{\text {th }}$ to $12^{\text {th }}$ day of inoculation. The details of growth of leptospires are shown in Table. 2 \& Fig. 1 . 


\section{International Journal of Science and Research (IJSR) \\ ISSN (Online): 2319-7064}

Index Copernicus Value (2013): 6.14 | Impact Factor (2014): 5.611

Table 2: Growth pattern of Leptospiral vaccine strains in Low Protein medium (0.2\%BSA)

\begin{tabular}{|c|c|c|c|c|}
\hline \multirow{2}{*}{ S. No } & Indicating & \multicolumn{3}{|c|}{ No. of leptopsires in millions per ml } \\
\cline { 3 - 5 } & percent & Autumnalis & Grippotyphosa & Hardjo \\
\hline 1 & 0 & 8.5 & 8.0 & 9.0 \\
\hline 2 & 1 & 17.0 & 16.5 & 18.5 \\
\hline 3 & 2 & 26.5 & 27.5 & 32.0 \\
\hline 4 & 3 & 37.0 & 40.0 & 43.5 \\
\hline 5 & 4 & 98.5 & 121.5 & 119.0 \\
\hline 6 & 5 & 123.0 & 160.0 & 145.5 \\
\hline 7 & 6 & 195.5 & 290.0 & 230.0 \\
\hline 8 & 7 & 340.0 & 474.0 & 435.0 \\
\hline 9 & 8 & 876.5 & 1025.0 & 980.5 \\
\hline 10 & 9 & 1825.0 & 235.0 & 225.0 \\
\hline 11 & 10 & 2850 & 3100 & 3200 \\
\hline 12 & 11 & 3200 & 3450 & 3675 \\
\hline 13 & 12 & 2725 & 2325 & 2550 \\
\hline 14 & 13 & 1900 & 1885 & 1975 \\
\hline 15 & 14 & 850 & 974 & 875 \\
\hline 16 & 15 & 230 & 310 & 280 \\
\hline
\end{tabular}

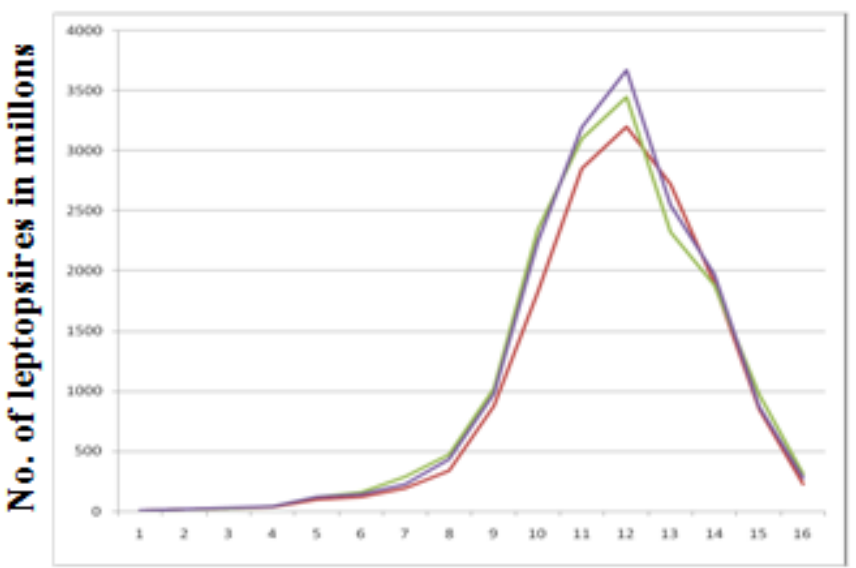

Number of days of incubation

- No. of Leptospira autumnalis per ml

No. of Leptospira grippotyphosa perml

No. of Leptospira hardjo per ml

Figure 1: Growth pattern of Leptospiral vaccine strains in low protein medium $(0.2 \% \mathrm{BSA})$

The leptospiral serovars namely L. grippotyphosa, L. hardjo and L. autumnalis adjusted to the concentration of $2 \times 10^{9}$ organisms $/ \mathrm{ml}$ were inactivated using $0.5 \mathrm{ml}$ of formalin for 24 hrs.

\subsection{Standardization of Vaccine}

Vaccine was prepared with inactivated leptospira using aluminium hydroxide (vaccine-I) and mountanide (vaccineII) as adjuvants. The adjuvanted vaccines, Vaccine-I (aluminium hydroxide) and Vaccine II (Mountanide) were tested for sterility, safety and potency.

\subsection{Sterility Test}

Blood agar, nutrient agar, sabroaud's agar and thioglycolate medium inoculated with vaccine-I and vaccine-II did not showed any growth of microorganisms and fungi during incubation of 14 days at $30^{\circ} \mathrm{C}$ and $37^{\circ} \mathrm{C}$ regularly.

\subsection{Safety Test}

All the four guinea pigs inoculated with the vaccine preprations did not show any local and systematic reaction and no elevated temperature up to 20 days, the period of observation. No gross lesions were observed in any of the organs in the guinea pigs sacrificed on $20^{\text {th }}$ day of inoculation. Examination of the liver and kidney tissue impression smears using ADMAS modified silver staining method did not reveal any leptospires.

\subsection{Potency Test}

The vaccinated guinea pigs with vaccine-I and vaccine-II challenged with virulent leptospires of autumnalis, hardjo and grippotyphosa did not show any clinical signs of leptospirosis where as un vaccinated animals die between 710 days after challenging with serovars grippotyposa and autumnalis. However, the guinea pigs challenged with hardjo did not die. The weekly mean body temperature $\mathrm{s}$ of the guinea pigs is presented in a table.3. An increase in body temperature in un-vaccinated animals was observed when compared with vaccinated animals after challenge.

The MAT titers against L. grippotyphosa, L. hardjo and $L$. autumnalis of vaccinated and un-vaccinated guinea pigs are shown in table.3.

Table 3: Potency test in Guinea pigs for evaluation of experimental leptospira vaccines

\begin{tabular}{|c|c|c|c|c|c|c|c|c|c|c|c|}
\hline \multirow{3}{*}{ S. No } & \multirow{3}{*}{ Test } & \multirow{3}{*}{ Sample examined } & \multicolumn{9}{|c|}{ Details of serovars } \\
\hline & & & \multicolumn{3}{|c|}{ Autumnalis } & \multicolumn{3}{|c|}{ Grippotyphosa } & \multicolumn{3}{|c|}{ Hardjo } \\
\hline & & & $V-I$ & $V I I$ & Control & $V I$ & $V I I$ & Control & $V I$ & $V I I$ & Control \\
\hline 1 & MAT & Serum on $14^{\text {th }}$ day & 4.78 & 4.87 & - & 4.85 & 4.89 & - & 4.77 & 4.83 & - \\
\hline 2 & GMT in $/ \log ^{2}$ & Serum on $35^{\text {th }}$ day & 4.86 & 4.86 & - & 4.78 & 4.87 & - & 4.82 & 4.87 & 4.81 \\
\hline
\end{tabular}

The MAT titers against $L$. grippotyphosa, $L$. hardjo and $L$. autumnalis in guinea pigs after 14 days of vaccination with vaccine-I was $4.78,4.77$ and 4.85 and with vaccine-II was $4.87,4.83$ and 4.89 respectively. The MAT titers on 20 days after post challenge with vaccine-I was $4.86,4.82$ and 4.78 and with vaccine-II was $4.90,4.87$ and 4.87 respectively.

The un-vaccinated control animals died within 7-10 days in case of autumnalis and grippotyposa but death was not observed in animals challenged with hardjo and further it induced antibody titer of 4.87 .

\subsection{Immune Response in Rabbits}

The antibody response in vaccinated rabbits was studied by using MAT and results are shown in table.4. 


\section{International Journal of Science and Research (IJSR) \\ ISSN (Online): 2319-7064}

Index Copernicus Value (2013): 6.14 | Impact Factor (2014): 5.611

Table 4: Immune response in rabbits against leptospira experimental vaccines

\begin{tabular}{|c|c|c|c|c|c|c|c|c|c|c|}
\hline \multirow{2}{*}{ S. No } & \multirow{2}{*}{ DPT } & \multicolumn{3}{|c|}{ Autumnalis } & \multicolumn{3}{c|}{ Grippotyphosa } & \multicolumn{3}{c|}{ Hardjo } \\
\cline { 3 - 13 } & & Vac-I & Vac-II & Control & Vac-I & Vac II & Control & Vac-I & Vac -II & Control \\
\hline 1 & 0 & - & - & - & - & - & - & - & - & - \\
\hline 2 & 7 & 4.77 & 4.83 & - & 4.73 & 4.78 & - & 4.74 & 4.81 & - \\
\hline 3 & 30 & 4.83 & 4.87 & - & 4.77 & 4.82 & - & 4.79 & 4.84 & - \\
\hline 4 & 60 & 4.87 & 4.90 & - & 4.85 & 4.89 & - & 4.86 & 4.88 & - \\
\hline 5 & 90 & 4.84 & 4.87 & - & 4.82 & 4.84 & - & 4.83 & 4.82 & - \\
\hline 6 & 120 & 4.79 & 4.84 & - & 4.76 & 4.84 & - & 4.78 & 4.81 & - \\
\hline 7 & 150 & 4.77 & 4.84 & - & 4.76 & 4.82 & - & 4.77 & 4.79 & - \\
\hline
\end{tabular}

The rabbits in the group-I received vaccine-I containing aluminium hydroxide responded to antigen showed the GMT $\log ^{2}$ titer of 4.77 to autumnalis, 4.74 to hardjo and 4.73 to grippotyposa on $7^{\text {th }}$ day. GMT $\log ^{2}$ titers of serum samples collected on $7^{\text {th }}$ day of post vaccinated in response to vaccine-II against $L$. autumnalis $L$. hardjo and $L$. grippotyphosa, were found to be $4.83,4.81$ and 4.78 respectively. The GMT $\log 2$ titer values against autumnalis, hardjo and grippotyposa were found to be 4.77, 4.77 and 4.76 respectively by day $150^{\text {th }}$ of the observation period for the vaccine $-\mathrm{I}$.

The rabbits in the group II receiving vaccine-II containing mountainde showed seroconversion to autumnalis 4.83 , hardjo 4.79 and grippotyposa 4.82 in response to vaccine-II by day $7^{\text {th }}$ (table..). In the group the peak GMT $\log 2$ titers against autumnalis (4.90), hardjo 4.88) and grippotyposa (4.89) were noticed on $60^{\text {th }}$ day. The GMT $\log 2$ titer values of $4.84,4.77$ and 4.82 were noticed against autumnalis, hardjo $\&$ grippotyposa on $150^{\text {th }}$ day post vaccination period Fig2.

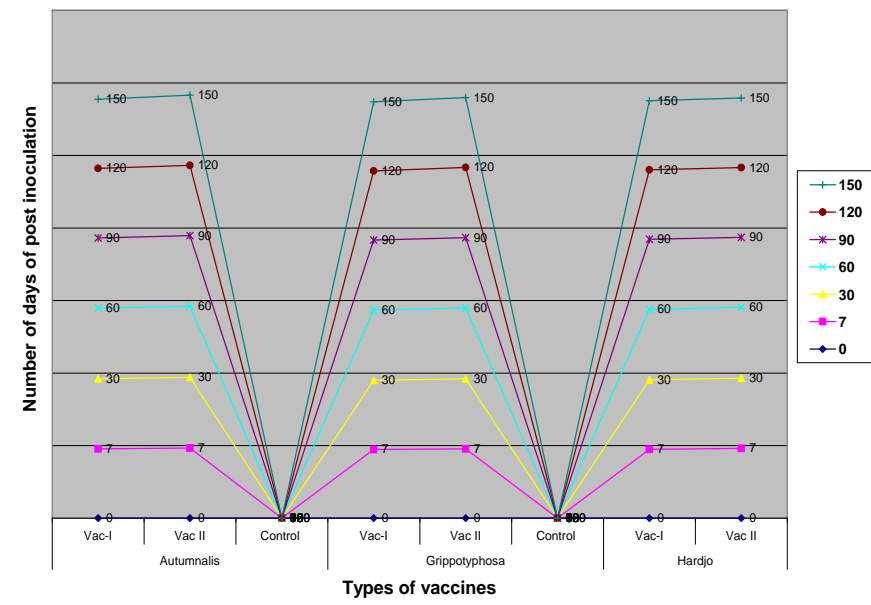

Figure 2: Immune response in rabbits against leptospiral Experimental Vaccines

\section{Discussion}

Leptospirosis can be prevented and controlled through active immunization. Seroepidemiological studies indicated the dominance of L. hardjo, L. grippotyposa and L.. autumnalis in the state. Hence, serovars L.hardjo, L. grippotyposa and $L$. autumnalis were selected as vaccine candidates for the preparation of trivalent inactivated vaccine.

In the present study vaccine strains were adopted to low protein medium containing $0.2 \% \mathrm{BSA}$ to minimize the adverse reactions such as pyrogenecity and dermal toxicity caused by serum albumin [3]. Adaptation of leptospires to low protein media did not alter the immunogenicity [1] Activated charcoal powder was used to reduce the toxicity of tween [3] Formalin at the concentration of 0.5 percent was used for inactivation of leptospiral organisms for the preparation of vaccine in the study. Earlier several workers were also used formalin as an inactivating agent in the preparation of leptospiral vaccine [15], [22], [13], [12] and [16]. Further, it was also reported that formalin treated antigen induces strong antibody response [18] and [14].

The vaccines thus prepared were evaluated for sterility, safety and potency tests. Under safety test, no raising temperature, local \& systemic reactions are seen in inoculated Guinea pigs and it is due to the usage of low protein medium for cultivation of vaccine strains. [8] was also used low protein medium for the growth of leptospiral while preparing the vaccine and obtained similar results.

Sterility of vaccine I (Alum), Vaccine II (Montenied) were checked using nutrient agar, blood agar, thioglycolate media and sabourauds dextrose agar media. Both the vaccines were found to be free from viable bacteria and fungi during incubation of 14 days at $30^{\circ} \mathrm{C}$ and $37^{\circ} \mathrm{C}$ respectively maximum period tested, meeting the requirements[5] and [9].

Potency of the vaccine is tested in guinea pigs by measure in antibody titers [16]. In the present study, the guinea pigs vaccinated with vaccine-I and vaccine-II were challenged after 14 days of post vaccination with virulent leptospires of L. autumnalis, L. hardjo and L. grippotyposa did not shown any clinical signs of leptospirosis indicating 100 percent protection. But, un vaccinated animals were died between 7 to 10 days after challenge with serovars L. grippotyposa and l. autumnalis, where as the guinea pigs challenged with.$L$. hardjo did not die and instead induces antibody titer of 4.81 (GMT $\log 2$ titers). This is in agreement with earlier report of [6]. Some strains may be virulent in some hosts but not in the experimental models. L.noguchii isolated from clinically suffering sheep fails to cause the disease in hamsters [21].

In vaccinated guinea pigs 14 days after vaccination antibody titer was measured using MAT. GMT $\log 2$ values of MAT titers against vaccine I were $4.78,4.77$ and 4.85 and with vaccine II 4.84, 4.83 and 4.89 respectively against autumnalis, hardjo and grippotyphosa. Similarly MAT titers (GMT $\log 2$ titers) on day $20^{\text {th }}$ of post vaccination with vaccine I were $4.86,4.82$ and 4.78 and with vaccine II were $4.90,4.82$ and 4.87 respectively. All the unvaccinated control guinea pigs died within 7 to 10 days in case of autumnalis and grippotyphosa and no death was observed in 


\section{International Journal of Science and Research (IJSR) ISSN (Online): 2319-7064}

Index Copernicus Value (2013): 6.14 | Impact Factor (2014): 5.611

guinea pig challenged with hardjo. Thus, vaccine I (aluminium hydroxide) and Vaccine II (Montanide adjuvanted ) full filled the criteria of potency suggested by [16].

Immune responses against two types of adjuvanted vaccines namely vaccine-I (aluminum hydroxide) and vaccine-II (mountanide adjuvanted) were studied in rabbits for a period of 150 days. Both the vaccines induced detectable level of antibodies against all the three serovars incorporated in the vaccine on day $7^{\text {th }}$ of post vaccination. The GMT $\log 2$ MAT titer values followed by vaccine-II was slightly higher than vaccine-I which is significant. The antibody response on the day $30^{\text {th }}$ to $90^{\text {th }}$ day was high against all the three serovars in both the vaccines and slight decrease in the antibody titer on the $20^{\text {th }}$ to $150^{\text {th }}$ day of immunization (table. $5 \&$ fig. 4 ). No statistical significant difference was observed in immune responses elicited by both the types of adjuvanted vaccines in rabbits. The antibody response was observed up to 150 days of post vaccination, the maximum period of study.

\section{References}

[1] B. Alder and S. Faine, "Serological and protective antibody responses of rabbits to leptospiral antigens", Journal of Medical Sciences, 11, pp. 401-409, 1978.

[2] J. Aucouturier, S. Ascarateil, S. O.'Neill, V. Ganne and A. Laval, "Vaccine adjuvants for bovine", Seppic, France, 2002.

[3] R. F. Bey and R. C. Johnson, "Protein-free and lowprotein media for the cultivation of Leptospira". Infectious Immunology, 19, pp. 562-569, 1978.

[4] R. F. Bey and R. C. Johnson, "Current status of leptospiral vaccines", Progress Veterinary Microbiology 2, pp. 175-197, 1986.

[5] British Pharmacopoeia (Veterinary) "Leptospira", Veterinary Vaccines, pp.117, 1985.

[6] D. M. Bulach , R. L. Zuerner, P. Wilson , T. Seemann, A. McGrath, P. A .Cullen, J. Davis, M. Johnson, E. D. P. Kuczek, Alt, B. Peterson-Burch, R. L. Coppel, J. I. Rood, J. K. Davies and B. Adler, "Genomic reduction in Leptospira. Borgpetersenii reflects limited transmission potential", Proceedings of the National Academy of Sciences, 103, pp.14560-14565, 2006.

[7] Z. T. Chen, "Development and present status of leptospiral vaccine and technology of production of the vaccine in China", Annales Immunologiae Hungaricae, 26, pp. 125-151, 1986.

[8] W. L. Christopher, B. Adler and S. Faine, "Immunogenicity of Leptospiral vaccines grown in protein - free medium", Journal Medicinal Microbiology, 15, pp. 493-501, 1982.

[9] Council of Europe, Monograph 01/2002.0447, "Leptospira vaccine for Veterinary use", European Pharmacopoeia. Fourth Edition of the Council of Europe, Strasbourg, France, pp .2270, 2002.

[10]H. Dikken and E. Kmety, "Serological typing methods of leptospires". In: T. Bergan and J. R. Norris, Methods in Microbiology, Vol.11, Academic Press, London, U.K, pp. 259-3071978.

[11] W. G. Hoag and W. B. Bell, “An immunogenic agent for protection of cattle against Leptospira Pomona",
American Journal of Veterinary Research, 16, pp. 381$385,1955$.

[12] N. Koizumi and H. Watanabe, "Leptospirosis vaccines: Past, present and future", Journal of Post Graduation Medicine 51, pp. 210-214, 2005.

[13] R. B. Marshall, "The epidemiology and public health aspects of leptospirosis in New Zealand", Australian Association of Cattle Veterinarians, Pan Pacific Proceedings pp.25-27, 1991.

[14] B. H. Naiman, D. All, C. A. Bolin, R. Zuerner and C. L. Baldwin, "Protective killed Leptospira borga petersenii vaccine induces potent Th1 Immunity comprising responses by CD4 and gamma delta T Lymphocytes", Infections and Immunity 69, pp. 7550-7558, 2001.

[15] L. Olitzki, L. A. Stuezynki, C. Halevi and H. Bernkipf, "Immunologic studies on bovine leptospirosis, "Journal of Infectious Diseases", 84, pp. 15-20, 1953.

[16] Office International-des-Epizooties, "Leptospirosis In: Manual of standards for diagnostic tests and vaccine", OIE, Paris, 2008.

[17]C. E. Phillips, "Leptospiral vaccine evaluation. Veterinary Medicine”, 53, pp. 301-307, 1958.

[18] V. Pope and R. C. Johnson, "Effect of heat of formalin treatment of Leptospires on antibody response detected by immunoblotting", Journal of Clinical Microbiology, 29, pp. 1548-1550, 1991.

[19] I. Samina, J. Brenner, U. Moalem, M. Berenstain, A. Cohen and B. A. Peleg, "Enhanced antibody responses in cattle against leptospira hardjo by intradermal vaccination", 15, pp. 1434-1436, 1997.

[20] Seppic, P/1924/GB/01/ January, 2002.

[21] E. F. Silva, C. S. Santos, D. A. Anthanazio, N. Segffert, F. K. Seixas, G. M. Cerqueira , M. Q. Fagundes, C. S. Brod, M. G. Reis O. A. Dellagostin and A. I. Ko, "Characterization of virulence of leptospira isolates in hamster model”, Vaccine, 26, pp. 3892-3896, 2008.

[22] A. B. Thiermann, "Leptospirosis: Current developments and trends", Journal of American Veterinary Medicine Association, 184, pp. 722-725, 1984.

[23] J. M. Vinetz, "Leptospirosis", Current Infectious Disease, 14, pp. 527-538, 2001.

[24]Zhijun wang, Lijin and Alicja Wegrzyn, Review article, "Leptospirosis vaccines".

\section{Author Profile}

Dr. D. Rani Prameela received Bachelor degree of Veterinary and Animal Sciences in 1990, Masters in Veterinary Microbiology in 1992 and Doctoral degree programme in 2010 at College of Veterinary Sciences, Sri Venkateswara Veterinary University, Tirupati and worked as Assistant Professor from 2001 to 2012 and Associate Professor from 2012 to till date. Presently working as Head at State Level Animal Disease Diagnostic Laboratory, Sri Venkateswara Veterinary University, Tirupati, Andhra Pradesh, India. 